\title{
THE MEDICAL TREATMENT OF ULCERATIVE COLITIS
}

\author{
Geoffrey Watkinson, M.D.(Lond.), F.R.C.P.(Lond.) \\ Consultant Physician to the York Hospitals
}

THE medical management of ulcerative colitis is a difficult and diffuse topic. The assessment of any measure is a complex task in a disease which varies greatly in severity and extent not only from patient to patient but in the same individual from attack to attack. The physician possesses a variety of drugs capable of inducing remission in perhaps half the cases treated but has no reliable way of predicting the therapeutic outcome in a particular instance.

In treating the colitic patient, the physician is faced with three duties, firstly in terminating the acute attack or exacerbation of colitis as quickly as possible, secondly in attempting to prevent recurrent attacks by some form of maintenance treatment, and thirdly, realizing that his therapeutic measures often fail, in knowing when to call in the surgeon. He should constantly be asking himself whether his efforts are prejudicing the outcome of surgery or the long-term well being of the patient.

Experience of treating over 300 colitic patients attending hospitals in Leeds and York over the last I 3 years has given some insight into the common problems of the management of these patients.

\section{Termination of an Acute Colitic Attack or Exacerbation \\ General Principles}

In managing an acute attack of colitis the following general principles are adopted:

(I) Rest of body, mind and gastrointestinal tract is attempted.

(2) Diet. It is first necessary to maintain fluid and electrolyte balance, losses particularly of potassium being excessive. It follows, in acute disease, that frequent biochemical estimations of serum electrolyte levels are necessary and that intravenous replacement is frequently necessary.

A high calorie, high protein low residue diet of 2,000 to 3,000 calories is essential with vitamin supplements of folic acid, vitamin $B$ and even vitamin $B_{12}$ given if necessary parenterally. I have had little experience of intravenous parenteral feeding (Wilkinson, r96r) but have found it a little disappointing in debilitated post-operative patients, nor have I found anabolic agents helpfut $\vec{\omega}$ in wasted patients.

Interest in dietary treatment has been re awakened recently by Truelove's observations or the role of milk in causing and exacerbating colitic attacks. Truelove (1961) first reporteds five patients in whom the introduction of millos containing foods into their diets repeatedly in duced relapses of their colitis whereas they re $-\infty$ mained well if maintained on a milk-free low residue diet. He supported his contention on the harmful effects of milk by showing, in conjunctiono with Dr. Keith Taylor, that the blood of a signi- $\AA^{\infty}$ ficantly greater proportion of colitic patie日s contained a high titre of antibodies to malk proteins than did the blood of matched contioto patients. Thus, $43 \%$ of 75 colitic patie showed titres of antibodies to milk protemis exceeding $1 / 20,000$ as compared with $8 \%$ of controls (Taylor and Truelove, 196r). The presence of antibodies in colitic patients could nok be related to age, sex, extent of disease, previouso steroid therapy or activity of the disease but it appeared that high titres were only observed ing patients with longstanding chronic disease. Colitic patients appeared to become sensitized to milk by bottle-feeding in the first month of life as significantly greater proportion of colitic patients had been weaned early (Acheson and Truelove1961).

Milk allergy may then be an important factor in the causation of colitis and the exclusion of milks products from the diet of the colitic patient of valuable therapeutic measure. It might be possible, in the future, to screen colitic patients byo examination of their blood for milk antibodies, en forcing a milk free diet in the proportion showing high titres of antibodies. The results of further work on this interesting new aspect of therapy iñ colitis will be eagerly awaited.

(3) Symptomatic drugs. It may be necessary, to control diarrhœa, to use a variety of gastroin $\frac{}{\Phi}$ testinal sedatives and astringents such as kaolin@्? codeine and morphia derivatives. Such drugs are not without risk when administered to patient $\Phi$ 
withrencute colonic dilatation. Antispasmodics, such as belladenal retard and propantheline bromide, are useful in controlling the colicky pain which is such a disability to the patient. Sedatives such as phenobarbitone and amylobarbitone are used in the anxious subject while methods to combat anæmia are vigorously applied. Ferrous fumurate orally is best tolerated by the colitic patient but some patients are upset by any type of iron by mouth when parenteral therapy is advised.

(4) Blood transfusion. Transfusions of whole blood repeated as often as is necessary are of great importance and value, being a source both of hæmoglobin and of nitrogen to help replete the falling protein stores of the body.

(5) Sulphonamides. Sulphonamides in the form of sulphaguanidine, sulphasuxidine and phthalylsulphathiazole, for so long the mainstay of treatment in colitis, have now largely been replaced by sulphasalazine but : are sometimes used with oral steroids where they tend to reduce the occurrence of suppurative perianal complications.

(6) Antibiotics. . Antibiotics should be used with caution in the colitic patient as they may both cause diarrhœa themselves and predispose to secondary infection with monilial organisms. However, used discriminately in the febrile toxic patient they can be of considerable value provided they are given in short courses and administered parenterally. I have found neomycin, streptomycin, tetracycline and chloramphenicol of most value. Absorption from the denuded ulcerated colon may be abnormally great and a few cases of renal tubular damage have followed treatment of colitis with the supposed non-absorbable drug neomycin. The value of antibiotics in colitis is therefore limited but they may be of value in the acute attack or as a pre-operative measure.

(7) Psychotherapy. There are many colitic patients who benefit from psychotherapy but others in whom even taking a detailed psychiatric history may prove harmful. The dangerous potentialities of the disease must never be forgotten and if psychotherapy is to be practised it should be used in conjunction with other methods of medical treatment by a physician capable of recognizing and treating any complications that may arise. It is best applied therefore by the physician or gastroenterologist personally treating the patient and there is little place for the specialized psychotherapist. Thus, Paulley (1950) was able to cure or control 3 I of 42 patients treated; Grace, Pinsky and Wolff (1954) obtained good results in II of 19 patients treated, while Groen and Bastiaans improved or cured 18 of 33 patients treated. I can do no better than to quote from Dr. Groen's common-sense appraisal of the role of psychotherapy in colitis who states (Groen, I96I):

IIn general it is not the psychiatrist but the gastroenterologist, the physician or the family doctor who, according to our experience should treat his patient with a simple form of psychotherapy consisting of giving the patient time, kindness, tangible signs of understanding and support in his conflicts with his family, with his employers or even with other doctors and nurses. In short, it is the same approach of sympathetic listening and making things easier for the patient that is used by any good family doctor in his daily work'. Groen wonders 'How much of the beneficial effects obtained by drugs were actually achieved by the application of the drug which every doctor gives to a patient he is interested in, namely, himself'.

\section{Drugs Capable of Terminating the Acute Colitic Episode}

Two groups of drugs have been shown on critical appraisal to be capable of terminating the acute colitic attack in a significant proportion of patients treated, namely sulphasalazine, and the steroid group of drugs administered systemically or topically.

\section{Sulphasalazine}

Sulphasalazine or ' salazopyrin ', or ' asulfidine ', was introduced in the treatment of colitis by Professor Nanna Svartz in Sweden in 1940. As an azo-compound of salicylic acid and sulphapyridine, the drug has an affinity for connective tissue and has proved of value in both rheumatoid arthritis and ulcerative colitis. It is usually employed in a dosage of between 4 and $8 \mathrm{gm}$. daily, its use being limited by the development of side effects in about one in six patients treated. Side effects induced include nausea, indigestion, headache, drowsiness, drug fever, skin rashes and blood dyscrasias (Svartz, I96r).

The immediate results obtained by various workers by treating ulcerative colitis with sulphasalazine are detailed in Table $\mathbf{I}$.

It will be seen that in the 809 patients reviewed good results were obtained in between one-half and three-quarters of those treated, the incidence of side effects varying between $16 \%$ and $22 \%$. Sulphasalazine, however, proved less effective than combined topical and systemic steroid therapy when critically assessed recently in a careful controlled trial in 1 i 6 patients (Draper, Truelove and Watkinson, 1962). Thus clinical remissions followed the administration of steroids in $6.5 \%$ as compared with $50 \%$ induced by sulphasalazine while $79 \%$ of steroid treated cases showed mucosal improvement as compared with $43 \%$ of those 
TABle I

IMmediate Results of Treatment and THE Frequency of Drug Intolerance in Acute Colitic EPISOdes in 809 Patients Treated in Sweden, America and ENGLAND. REMISSIONS WERE INDUCED IN FROM ONEhalf to Three-Quarters of Patients Receiving the DRUG

\begin{tabular}{|c|c|c|c|}
\hline & $\begin{array}{l}\text { Patients } \\
\text { Treated }\end{array}$ & $\begin{array}{l}\text { Percentage } \\
\text { Recovered } \\
\text { or Much } \\
\text { Improved }\end{array}$ & $\begin{array}{l}\text { Percentage } \\
\text { Showing } \\
\text { Drug } \\
\text { Intolerance }\end{array}$ \\
\hline $\begin{array}{l}\text { Svartz (1956, 1961) } \\
\text { Morrison (1953) .. } \\
\text { Moertel and Bargen }\end{array}$ & $\begin{array}{r}439 \\
60\end{array}$ & $\begin{array}{l}77 \% \\
70 \%\end{array}$ & $\begin{array}{r}\text { 'Few' } \\
21 \%\end{array}$ \\
\hline $\begin{array}{l}\text { (1959) } \\
\text { Watkinson (196rb)... } \\
\text { Draper,Truelove and } \\
\text { Watkinson (1962) }\end{array}$ & $\begin{array}{r}183 \\
69 \\
58\end{array}$ & $\begin{array}{l}64 \% \\
47 \% \\
50 \%\end{array}$ & $\begin{array}{l}17 \% \\
16 \% \\
22 \%\end{array}$ \\
\hline
\end{tabular}

treated with sulphasalazine. Lennard-Jones, Longmore, Newell, Wilson and Jones (1960) were always able to demonstrate an advantage for oral prednisone over sulphasalazine when they compared the two drugs in two groups of 20 patients. However, sulphasalazine emerges as a useful drug in the treatment of colitis with at least even chances of success in the immediate termination of the acute colitic attack. Salazodimidine is a similar compound of greater potency for which a reduced frequency of side effects is claimed. This drug is still under evaluation; in my limited experience nine of 20 treated patients showed remissions.

\section{Systemic Steroid Treatment}

A succession of careful controlled trials have established that systemic steroids are capable of terminating acute exacerbations of ulcerative colitis. Notable amongst these were the trials organized by the Medical Research Council between $195^{\circ}$ and $195^{8}$, in which I had the pleasure of participating, which I will now briefly detail. It was first established that the $41 \%$ remission rate induced in 109 patients treated with daily $100 \mathrm{mg}$. doses of cortisone was significantly better than the $16 \%$ remission rate observed in ror patients receiving inert tablets. Patients with first attacks of colitis did better than relapsing cases both immediately and in long-term follow-up and at all grades of severity the cortisone-treated group recovered more completely and more frequently than the controls.

When the response of 85 colitic patients treated with a larger dose of cortisone of $200 \mathrm{mg}$. daily was compared with a similar number receiving 80 units of corticotrophin daily, corticotrophin was shown to possess a significant advantage, remission being induced in three in every five patients receiving it as compared with two in every five patients receiving cortisone. In this instance the response of first attacks to both agents was 3 comparable, $50 \%$ and $42 \%$ respectively, but $\stackrel{\mathbb{\Phi}}{\circ}$ chronic colitic patients treated with corticotrophin $C$. showed a significant advantage over those treated $\overrightarrow{\vec{F}}$ with cortisone, remissions occurring in $70 \%$ and $\stackrel{\%}{?}$ $37 \%$ in each instance (Truelove and Witts, 1955, 등 1959).

It appeared that results marginally better might $\frac{\overline{\frac{N}{\sigma}}}{\bar{\sigma}}$ be obtained by employing larger doses of corti- $\varrho$ cotrophin, Spencer, Kirsner, Mlynaryk, Reed and $\%$ Palmer (1962) claiming a remission rate of $68 \%$ in $\overrightarrow{0}$ 340 patients treated while Lennard-Jones and Vivian (196r) have suggested that in severe $\vec{\omega}$ fulminating disease remissions may be induced by a dosage of 120 units of ACTH which will not $\frac{0}{7}$ respond to 80 units-however this has not been my experience and it appeared from the M.R.C. trials $\infty$ that dosage did not modify the therapeutic $\vec{f}$ outcome.

The results obtained by more modern steroid $\infty_{\infty}^{\infty}$ compounds have been less well appraised, good results being claimed for prednisone and triamcinolone in comparable dosage (Lennard-Jones and $\vec{\nabla}$ others, 1960). My own experience of prednisone $\mathbb{D}$ has been similar to that of Truelove (1960), re- $\stackrel{\mathbb{D}}{3}$ missions occurring in about a third of those patien treated.

Cortisone, I think, should be the drug of choise in the average acute colitic attack, corticotrophi ? being reserved for fulminating attacks and preç. nisone for milder attacks and for out-patient usage.

What are the costs of steroid therapy? In the M.R.C. trials the exhibition of cortisone halved the early mortality and recourse to surgery, the mortality in the cortisone treated group being $4.6 \%$ and for those in the control group $10.9 \%$, $14.9 \%$ of the control group requiring early surgery as against $8.3 \%$ in those receiving steroids. Perforation must be accepted as a hazard in between $2 \%$ and $4 \%$ of acute fulminating colitic attacks and no evidence was accumulated to attribute this complication to steroid therapy (Truelove and Witts, 1955; Goldgraber, Kirsner and Palmer, 1957). It appeared that suppurative perianal complications were more common in both cortisone treated groups in each trial making it desirable to combine steroid therapy with a sulphonamide or with sulphasalazine. Complications of steroid therapy itself in the way of facial mooning, electrolyte disturbances and mental N illness were more apparent with treatment with corticotrophin constituting some disadvantage to its use.

\section{Topical Steroid Treatment}

Prompted by favourable results obtained by the 
TABLE 2

Clinical Outcome in 114 Patients with Fulminating Acute Attacks of Colitis. The High Mortality and Frequency to Recourse to SURGery WILl Be Noted

Clinical Outcome in Acute Fulminating Colitis

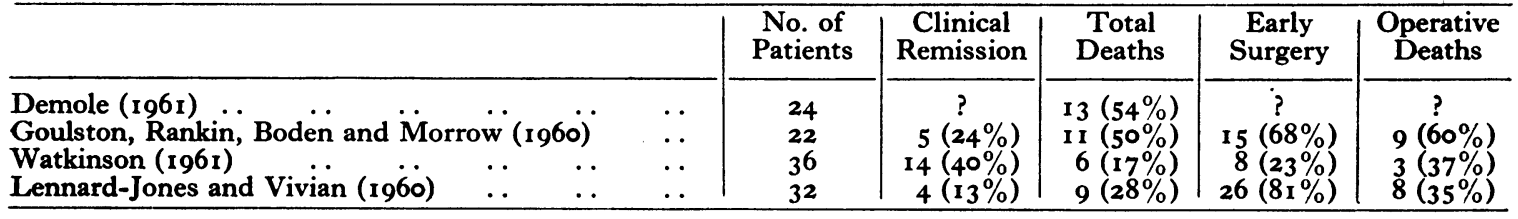

use of topical hydrocortisone in skin, eye and joint disease, Truelove in 1955 first advocated its topical use in ulcerative colitis. Subsequently a number of controlled trials have confirmed its value (Truelove, 1955, 1958; Watkinson, 1958, 1961 ; Matts, 1960; Matts and Gaskell, 1961) alone or in conjunction with oral prednisone (Truelove, 1960). Truelove (1961) and Matts (1962) have advocated topical steroids in acute fulminating disease but its main indication is in patients with colitis of mild to moderate severity with predominantly distal involvement.

Steroids can be administered topically as a rectal drip or by a plastic enema bag containing $100 \mathrm{mg}$. of hydrocortisone hemisuccinate sodium, $20 \mathrm{mg}$. of prednisolone-2I-phosphate or, most recently, 2.5 to $10 \mathrm{mg}$. of betamethasone. The retention of the rectal infusion can be facilitated by the preliminary administration of an antispasmodic such as propantheline bromide. Truelove in the course of various trials conducted between $195^{8}$ and 1960 has reported remission in between $69 \%$ and $75 \%$ of colitic patients treated with hydrocortisone, while Matts (196I) achieved a remission rate of $88 \%$ in 100 patients treated with prednisolone. The methods have fared less well in my hands, remissions occurring in $52 \%$ of those treated by topical methods. Suppositories containing $5 \mathrm{mg}$. of prednisolone proved helpful in patients with hæmorrhagic proctocolitis.

One of the advantages of topical steroid therapy has been the fact that the compound is not absorbed and side effects were not observed. When betamethasone, a steroid 50 times more potent than hydrocortisone, was used for topical treatment an excellent remission rate was obtained when doses of between 5 and $10 \mathrm{mg}$. were employed but side effects in the way of face mooning and skin acne developed in all patients. Reduction of dosage to $4 \mathrm{mg}$. halved the frequency of side effects but proved only half as effective in producing clinical remissions (Matts, 1962). It appears therefore that these more potent steroids will therefore have to be used with greater caution topically then heretofore.
Combined Topical and Systemic Steroid Treatment

Truelove in 1960 felt he had achieved the best results to date in treating colitic patients by combining topical treatment, by a rectal drip containing $100 \mathrm{mg}$. of hydrocortisone, with $20 \mathrm{mg}$. of prednisone by mouth. Recently, Draper, Truelove and Watkinson compared this combined treatment with salazopyrin by a controlled trial employing sequential analysis. Sixty-five per cent. of $5^{8}$ patients treated with steroids developed clinical remissions and $79 \%$ showed a significant lessening of mucosal inflammation, results which were significantly better than those achieved with sulphasalazine (Draper, Truelove and Watkinson, 1962).

Topical treatment therefore, alone or with oral prednisone, emerges as a valuable measure in colitis of any type or severity but is particularly of value in colitis of moderate severity and predominantly distal involvement.

\section{The Management of the Acute Fulminating Attack}

Acute fulminating colitis is a serious disease, carrying a high mortality, to which the gloomy experiences of many authors attest (Table 2). Here it emerges that mortalities varying between $17 \%$ and $54 \%$ are reported, that emergency surgery is frequently required and that operation in a debilitated patient of this type carries an alarming mortality varying between $35 \%$ and $60 \%$. The poor results of medical treatment made Goulston and others (1960) advocate the routine use of surgery in this type of patient (Table 2).

I would agree with them that cases of this type should be managed jointly from the outset by physician and surgeon. All available methods of medical treatment should be given to the patient. Vigorous attempts should be made to keep pace with losses of hæmoglobin, fluid, electrolytes and protein. A blood culture should be performed as an E.coli septicæmia is not uncommon in this type of case. Occasionally resolution of emotional 
factors precipitating the attack may be attempted. Corticotrophin, in a dosage of 80 to 120 units daily, is given together with $200 \mathrm{mg}$. of cortisone by mouth for four to seven days, while the effects of the corticotrophin become apparent. Salazopyrin is given by mouth in full dosage and if rectal hydrocortisone can be retained, this is also given nightly.

This treatment should be continued for up to two weeks, the possibility of operation being constantly reviewed. Surgery is indicated if no dramatic improvement follows medical treatment for seven to ten days, if the patient's condition deteriorates at any time under treatment and if a relapse follows an initial improvement induced by corticotrophin.

Colectomy is the treatment of choice though there may be a place for ileostomy alone when at laparotomy the patient's general condition appears desperate or inspection suggests that the colon might perforate when mobilized.

\section{Maintenance Treatment}

Having controlled the acute colitic attack, the physician now attempts to prevent relapse by maintenance treatment, about which little controlled information is available. Many patients stay well if treated with sulphasalazine for long periods, Svartz (1956) claiming that three-quarters of I I9 patients followed for five years were still in remission, while Moertal and Bargen (1959) reported that $57 \%$ of 123 patients receiving sulphasalazine were well a year later. In my hands maintenance treatment with sulphasalazine prevented relapse in 31 of 57 patients treated for periods varying between six months and ten years.

In attempting to prevent relapse by steroid therapy one may follow two courses: either to give doses of steroids sufficiently large to suppress the disease, accepting a formidable array of side effects, a procedure followed by Kirsner and Palmer in Chicago, or, as most British gastroenterologists have done, attempt control on a small maintenance dose of steroids accepting an appreciable relapse rate and recourse to surgery but avoiding steroid complications.

By employing daily maintenance doses of ACTH of the order of 20 to 80 units or of prednisone in a dose of 15 to $30 \mathrm{mg}$., the workers at the Chicago clinic were able to maintain $38 \%$ of their 340 patients in remission for long periods while a further $28 \%$ remained improved. Surgery was infrequently required and a low medical mortality of around $7 \%$ achieved. However, side effects of varying severity developed in $85 \%$ of those treated. These included psychological upsets in $16 \%$, diabetes or glycosuria in $12 \%$, serious electrolyte upsets in $12 \%$ and osteoporosis in $4 \%$ Four patients, developed peptic ulcer and seven melæna while nine deaths could be attributed to steroid therapy. The authors feel that control of this dreaded disease is a reasonable reward for the side effects induced (Spencer and others, 1962). $\stackrel{\text { ? }}{\rightarrow}$

When the effect of a $50 \mathrm{mg}$. maintenance dose of steroids was assessed by a controlled trial (Truelove and Witts, 1959) no difference in relapse rates? could be shown in two groups of patients receivingo potent and inert tablets for one year, remissionses being maintained in about half the patients in each $\vec{\circ}$ group. Those who had received corticotrophin: initially seemed to relapse earlier and more fre $\vec{w}$ quently than those treated initially with cortisone My own experience has been similar, for of 650 patients maintained on small doses of steroids over. ten years there have been 30 medical failures while. $\omega$ 20 had required surgery. In the remainder gratifying remissions are maintained.

\section{Indications for Operation}

Colitic patients are best followed up at a com- 군 bined medical and surgical clinic where in dis $-\vec{\nabla}$ cussion with the surgeon the possibility of operation can be constantly reviewed.

Operation may be required in acute fulminatiकg colitis if perforation, severe hæmorrhage or progessive toxic dilatation occurs. If under intensiece medical treatment the patient's condition continues to deteriorate or a relapse occurs after an initio improvement surgery should be undertaken.

In chronic ulcerative colitis operation advised when the condition fails to respond too medical treatment and is inducing invalidism, $\frac{Q}{\mathbb{Q}}$ repeated hospitalization and loss of work, or if $\overrightarrow{\vec{A}}$ irreversible structural damage to the colon haso developed by stricture formation, pseudopoly- $-\frac{3}{-}$ posis, or if carcinoma is suspected. The presence of recurrent or intractable para-rectal disease with fistulæ and rectovaginal abscess is a frequent? indication. Occasionally uncontrollable systemic:complications, such as recurrent iritis or arthritis, $\underline{3}$. may occasion operation. . Children with the disease present particular problems as often their growth and endocrine maturation are retardedo while their age does not protect them from malignant change in the colon (Rosenqvist, Ohrling, Lagercrantz and Edling, 1959). For these reasons despite their tender years operation may have to be enforced.

Some surgeons have argued that previous steroid therapy adversely affects the outcome of $\omega^{-}$ surgery in the colitic patients by predisposing to hypotensive vascular collapse and rendering the bowel more friable and difficult to handle at? operation (Brooke, 1952). Our experience in Leeds has not supported this contention thougho 
the data is difficult to appraise. In 100 patients Professor J. C. Goligher performed colectomy as an elective procedure during a phase of quiescence of the disease. The operative mortality was greater in the 63 patients who had not been given steroids than in the 37 who had, namely three deaths as compared with no deaths, nor was there any difference in their post-operative course. In 4I patients operation was undertaken as an emergency or life-saving procedure for a fulminating exacerbation of the colitis. There were eight deaths in 28 patients who had been given steroids and the incidence of pre-operative perforation and post-operative complications was appreciably greater than in 13 patients who had not been given the drug. However, the data could not be easily compared in that the steroid treated group contained most of the severely ill patients. Ewart and Lennard-Jones (1960) encountered similar difficulties when they analysed the effect of corticosteroids on the outcome of surgery in I3 I patients undergoing colectomy at St. Mark's Hospital, London, between 195 I and 1959. While the mortality and post-operative morbidity were greater in urgent operations for fulminating disease, again far more of these patients were severely ill than among those who had not received cortisone. They felt that cortisone had probably no effect on the outcome of operation. In any patient who has ever received steroids cortisone should be given throughout the operative and postoperative period and used liberally intravenously if post-operative hypotensive collapse occurs.

\section{Summary}

The medical treatment of ulcerative colitis has been detailed based on the experience of treating 300 patients over the last 13 years.

Rest, appropriate diet, symptomatic drugs and blood transfusion are frequently required in acute exacerbations of the disease. Antibiotics used parenterally for short periods are useful in the febrile toxic case while common sense psychotherapy by the attending physician is frequently helpful.

Two drugs are capable of terminating acute colitic attacks, namely sulphasalazine and steroids given systemically or topically. The results of the short and long-term usage are detailed.

The indications for colectomy are detailed and the effect of previous corticosteroid therapy on the outcome of surgery discussed.

My thanks are due to Professor J. C. Goligher for his help in the management of our patients, to Dr. S. G. Flavell Matts, Dr. S. C. Truelove and Mr. G. Draper for allowing me to quote from their unpublished data.

This article is published by permission of the Editor of 'Medizinische Klinik'.

\section{REFERENCES}

Acheson, E. D. S., and Truelove, S. C. (1961): Early Warning in the Ætiology of Ulcerative Colitis: A Study of Feeding in Infancy in Cases and Controls, Brit. med.. ., ii, 929.

Brooke, B. N. (1952): The Management of an Ileostomy Including its Complications, Lancet, ii, 102.

Demole, M. (196I): Panel Discussion on Ulcerative Colitis, Proc. Int. Cong. Gastroenterology (Leyden), 1960, p. 500.

Draper, G., Truelove, S. C., and Watkinson, G. (1962): Unpublished data.

Ewart, W. B., and Lennard-Jones, J. E. (1960): Corticosteroids in Pre-operative Medical Management of Ulcerative Colitis: Do they Affect Surgical Success? Lancet, ii, 60.

Goldgraber, M. B., Kirsner, J. B., and PAlmer, W. L. (1957): The Role of ACTH and Adrenal Steroids in Perforation of the Colon in Ulcerative Colitis: A Clinical Pathologic Study, Gastroenterology, 33, 434.

Goulston, S. J. M., Rankin, J. G., Boden, R. W., and Morrow, A. W. (1960): Fulminant Ulcerative Colitis, Quart Э. Med., N.S., 29, 375.

Grace, W. J., Pinsky, R. H., and WolfF, H. G. (1954): The Treatment of Ulcerative Colitis II, Gastroenterology, 26, 462.

Groen, J. J. (196I): Panel Discussion on Ulcerative Colitis, Proc. Int. Cong. Gastroenterology (Leyden), 1960, p. 5 I I.

Lennard-Jones, J. E., and Vivian, A. B. (1960): Fulminating Ulcerative Colitis: Recent Experience in Management, Brit. med. $\mathcal{F}$., ii, 96.

- Longmore, A. J., Newell, A. C., Wilson, C. W. E., and Jones, F. Avery (1960): An assessment of Prednisone, Salazopyrin, and Topical Hydrocortisone Hemisuccinate Used as Out-patient Treatment in Ulcerative Colitis, Gut, $\mathbf{1}, 217$.

Matrs, S. G. F. (1960): Local Treatment of Ulcerative Colitis with Prednisolone-2 I-Phosphate Enemata, Lancet, i, 5 I7.

—, and Gaskell, K. H. (1961): Retrograde Colonic Spread of Enemata in Ulcerative Colitis, Brit. med. F., ii, 615

(1962): Unpublished data.

Moertel, C. G., and Bargen, J. A. (1959): A Critical Analysis of the Use of Salicylazosulfapyridine in Chronic Ulcerative Colitis, Ann. intern. Med., 51, 879. 
Morrison, L. M. (1953): Response of Ulcerative Colitis to Therapy with Salicylazosulfapyridine, Y. Amer. med. Ass. I5I, 366.

Paulley, J. W. (1950): Ulcerative Colitis: A Study of 173 Cases, Gastroenterology, 16, 566.

Rosenqvist, H., Ohrling, H., Lagercrantz, R., and Edling, M. (1959): Ulcerative Colitis and Carcinoma Colie Lancet, i, 906.

Spencer, J. A., Kirsner, J. B., Mlynaryk, P., Reed, P. I., and Palmer, W. L. (1962): Immediate and Prolonged $\overrightarrow{\overrightarrow{\vec{b}}}$ Therapeutic Effects of Corticotrophin and Adrenal Steroids in Ulcerative Colitis: Observations in $34^{\circ}$ Cases fo Periods up to Ten Years, Gastroenterology, 42, 113.

Svartz, N. (1956): The Treatment of Ulcerative Colitis, Gastroenterologia, 86, 683.

- (1961): Panel Discussion on Ulcerative Colitis, Proc. Int. Cong. Gastroenterology (Leyden), 1960, Amsterdam p. 484 .

Taylor, K. B., and Truelove, S. C. (1961): Circulating Antibodies to Milk Proteins in Ulcerative Colitis, Brit. med. Y.e़ ii, 924.

TrueLove, S. C. (1958): Treatment of Ulcerative Colitis with Local Hydrocortisone Hemisuccinate Sodium: A Reporit on a Controlled Therapeutic Trial, Ibid., ii, 1072.

- (1959): Suppository Treatment of Hæmorrhagic Proctitis, Ibid., ii, 955.

(1960): Systemic and Local Corticosteroid Therapy in Ulcerative Colitis, Ibid., i, 464.

- (1960): Local Corticosteroid Treatment in Severe Attacks of Ulcerative Colitis, Ibid., ii, I02.

- (1961): Ulcerative Colitis Provoked by Milk, Ibid., i, 154.

- and WrrTs, L. J. (1955): Cortisone in Ulcerative Colitis: Final Report on a Therapeutic Trial, Ibid., ii, 1041

- and - (1959): Cortisone and Corticotrophin in Ulcerative Colitis, Ibid., ii, 387.

Watkinson, G. (1958): Treatment of Ulcerative Colitis with Topical Hydrocortisone Hemisuccinate Sodium: Controlled Trial Employing Restricted Sequential Analysis, Ibid., ii, 1077.

(1961): Panel Discussion on Ulcerative Colitis, Proc. Int. Cong. Gastroenterology (Leyden), 1960, pp. 486, 504.-

- (1961): Medical Management of Ulcerative Colitis, Brit. med. F., i, 147.

Wilkinson, R. W. (196r): Parenteral Feeding: in Modern Trends in Gastroenterology, pp. 234-251. London Butterworths. 